\title{
Przewalskin B, A Novel Diterpenoid with an unprecedented Skeleton from Salvia przewalskii Maxim
}

Gang Xu, ${ }^{\dagger}$ Ai-Jun Hou, ${ }^{\ddagger}$ Yong-Tang Zheng, ${ }^{\S}$ Yu Zhao, ${ }^{\dagger}$ Xiao-Li Li, ${ }^{\dagger}$ Li-Yan Peng, ${ }^{\dagger}$ and Qin-Shi Zhao, ${ }^{*, \dagger}$

Supporting Information 


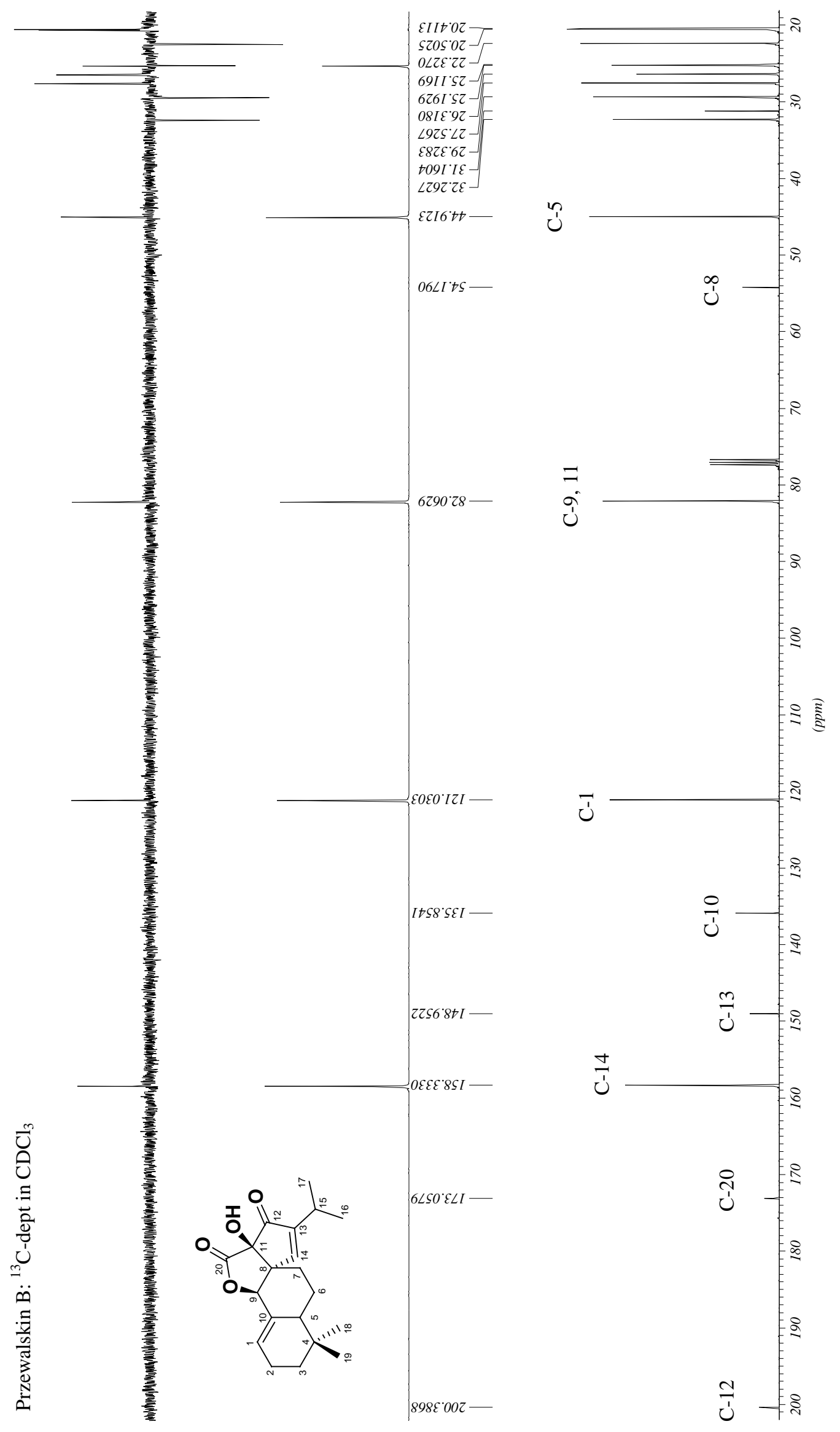




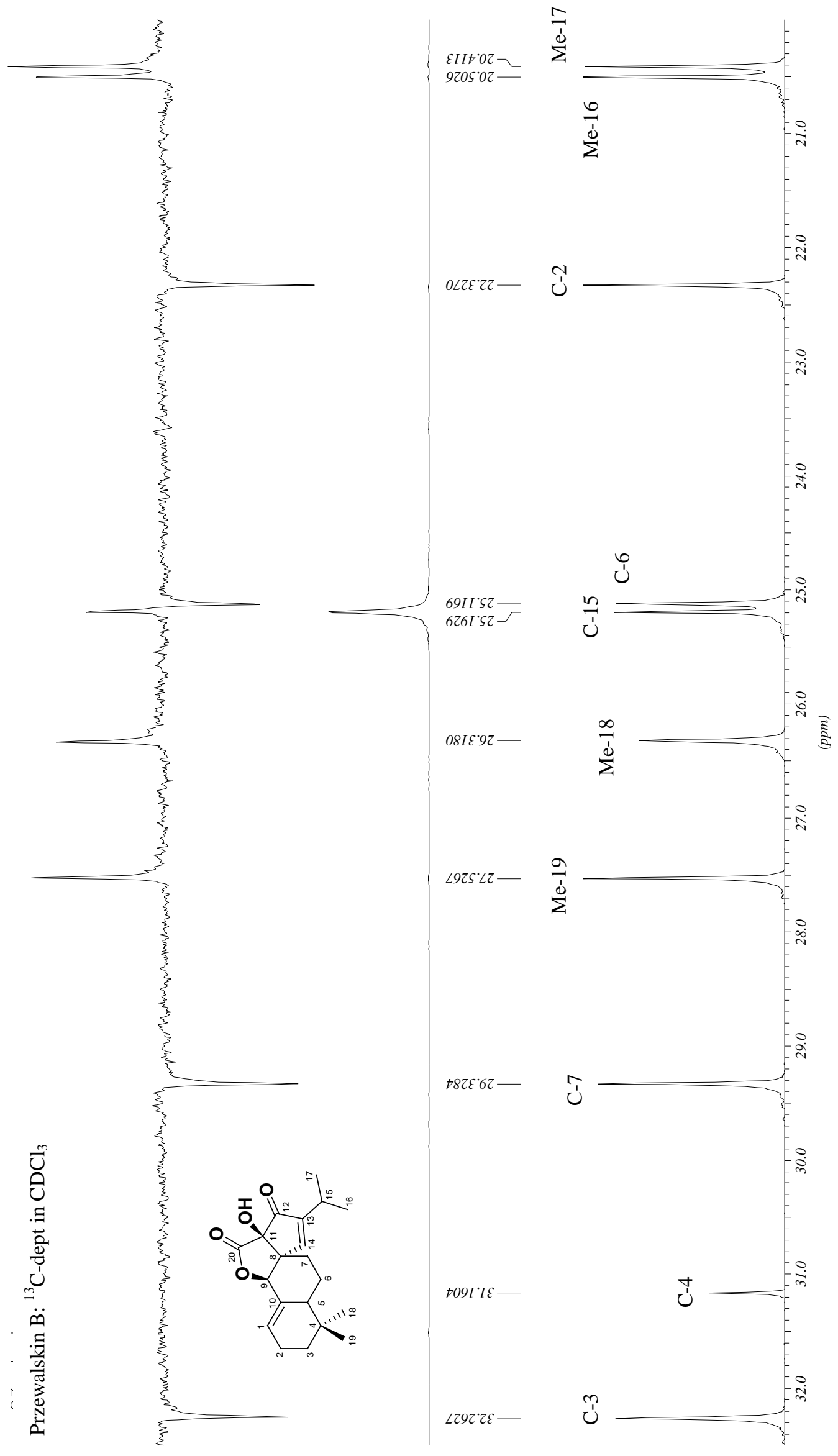




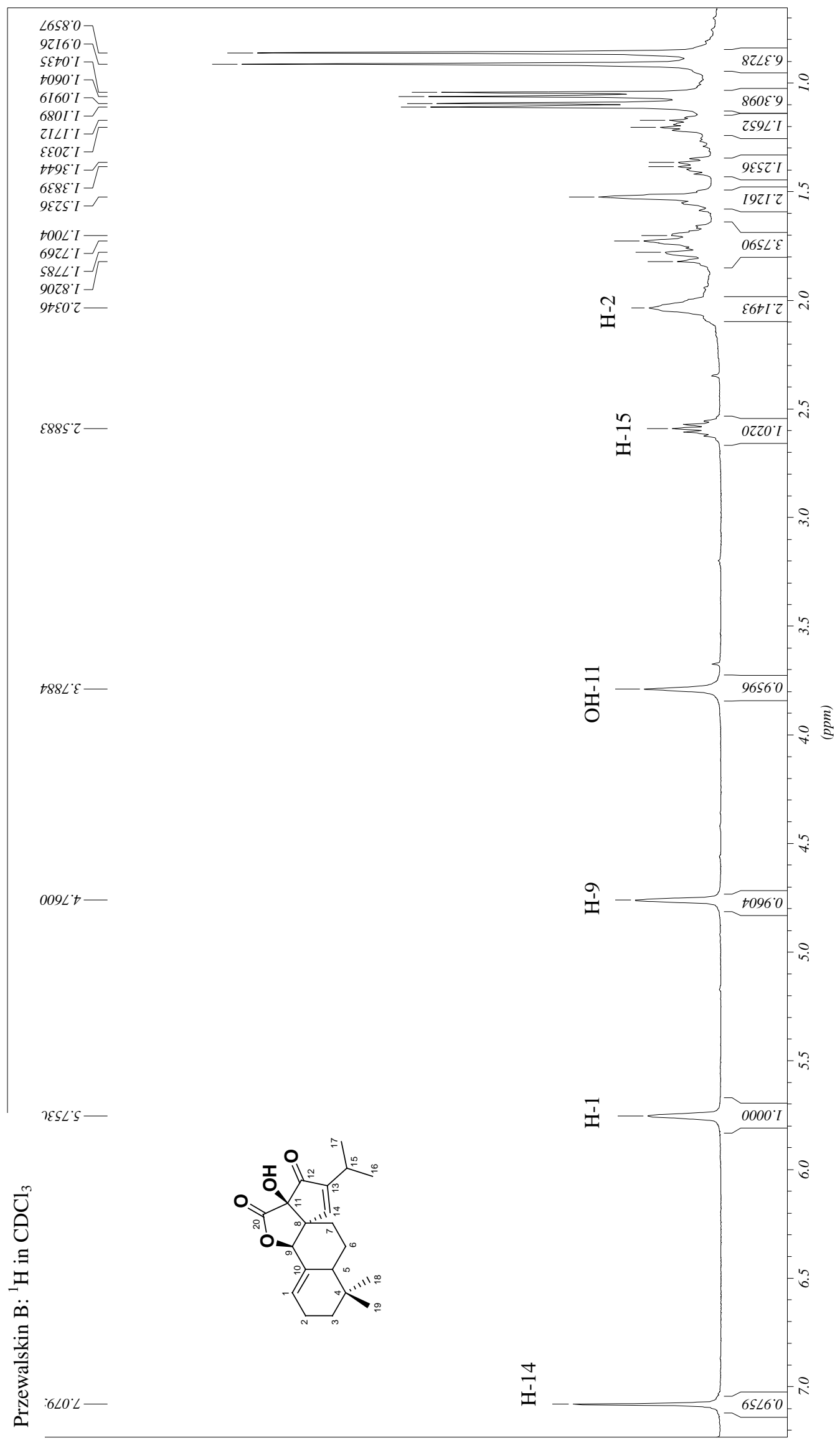




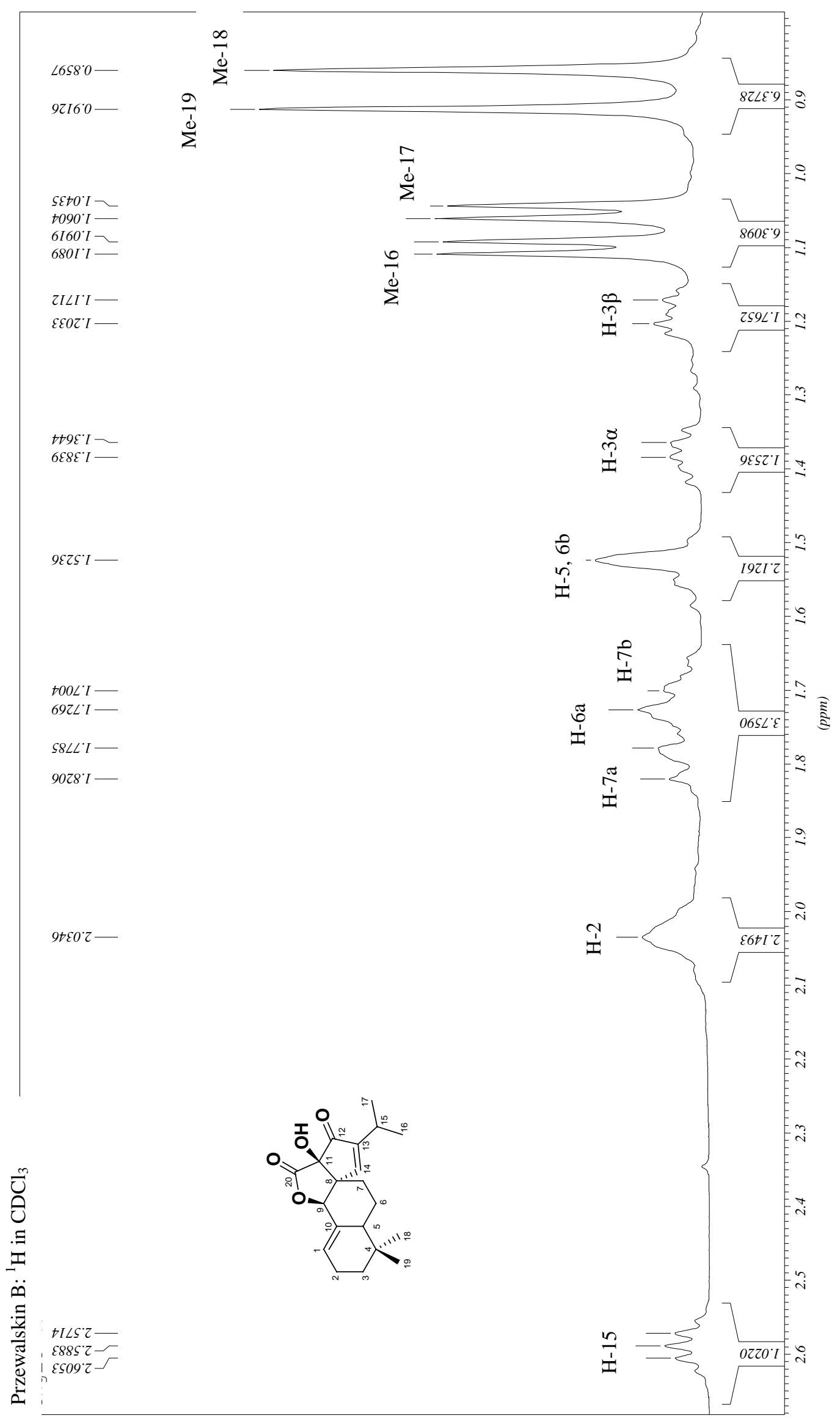




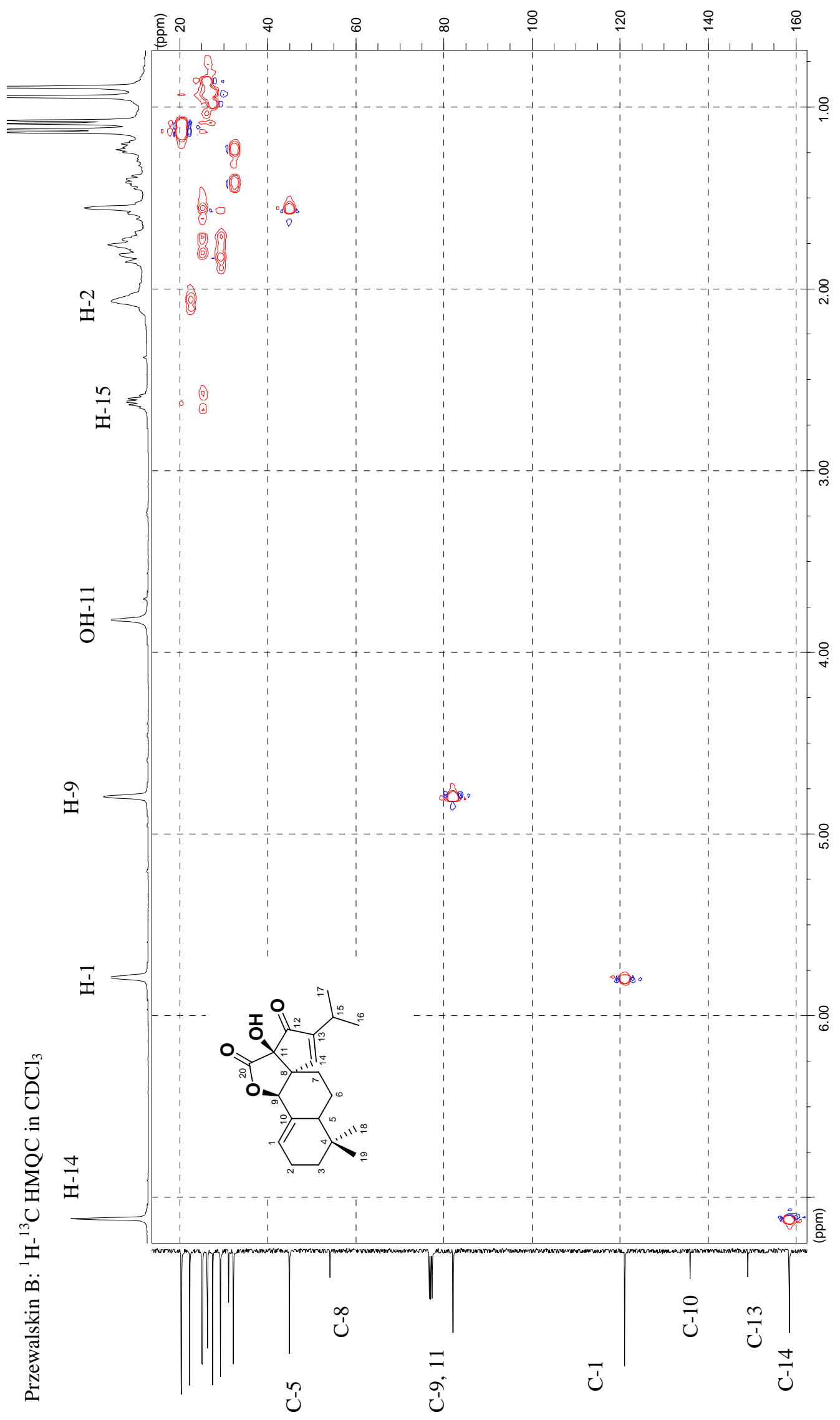




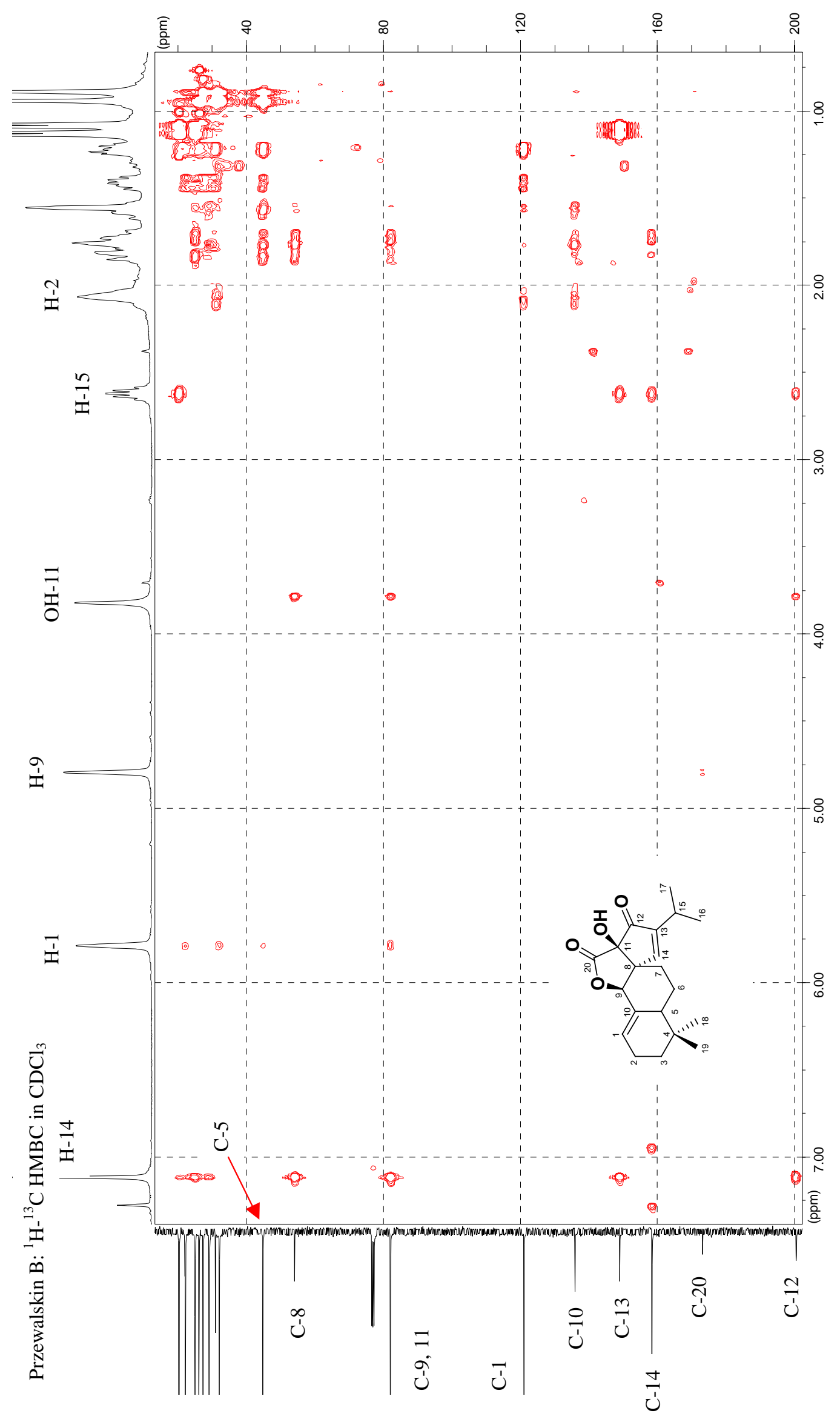




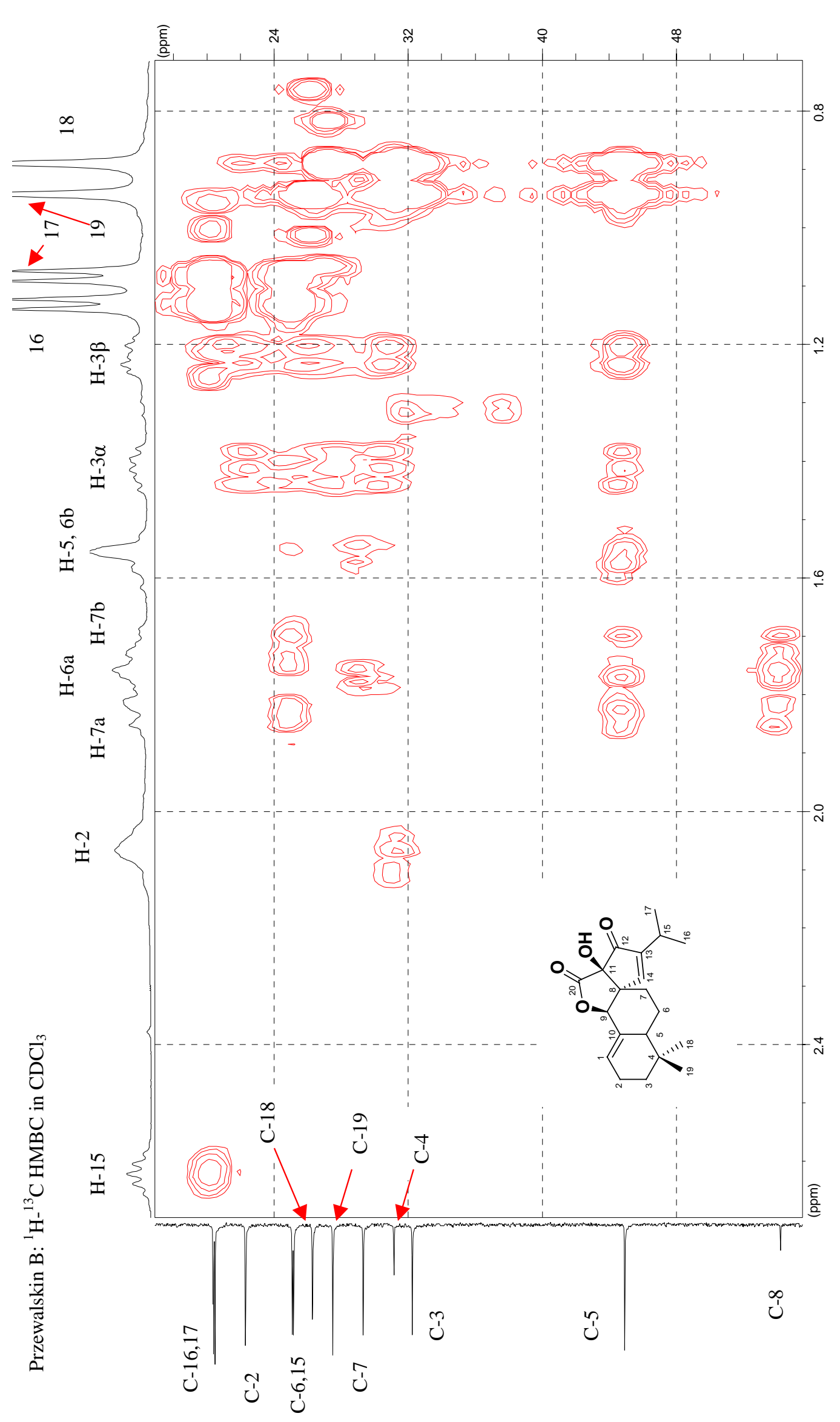




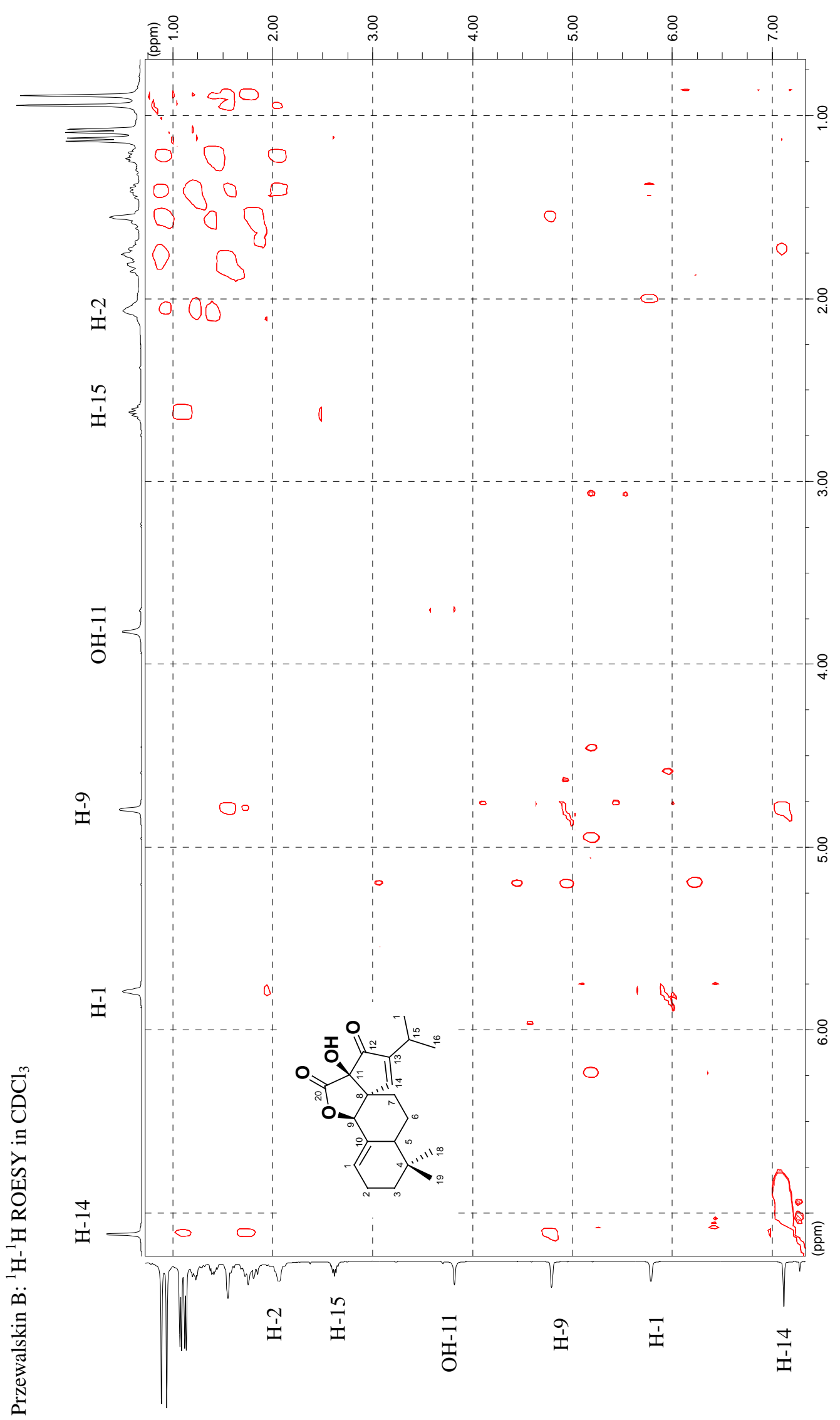




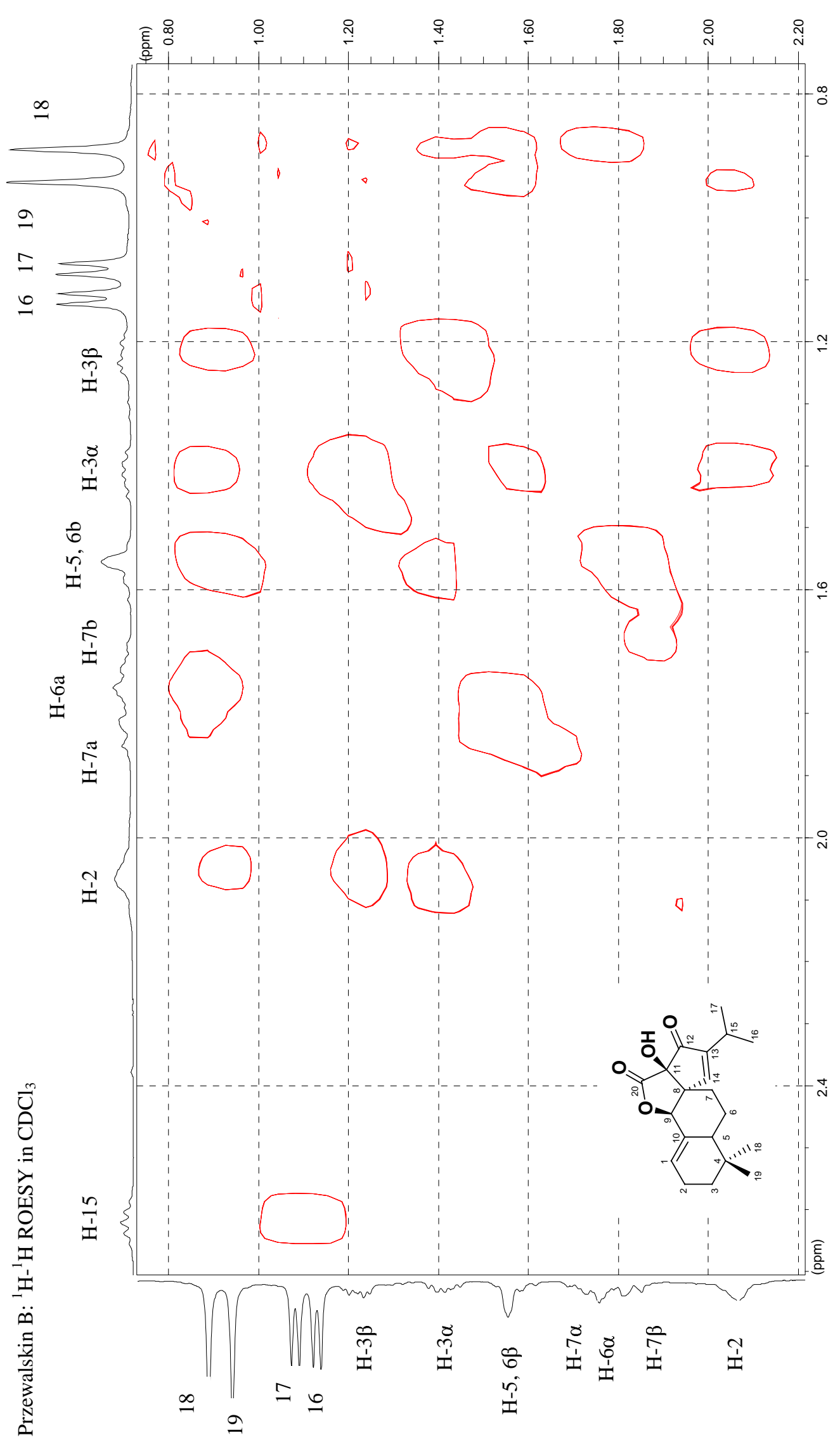




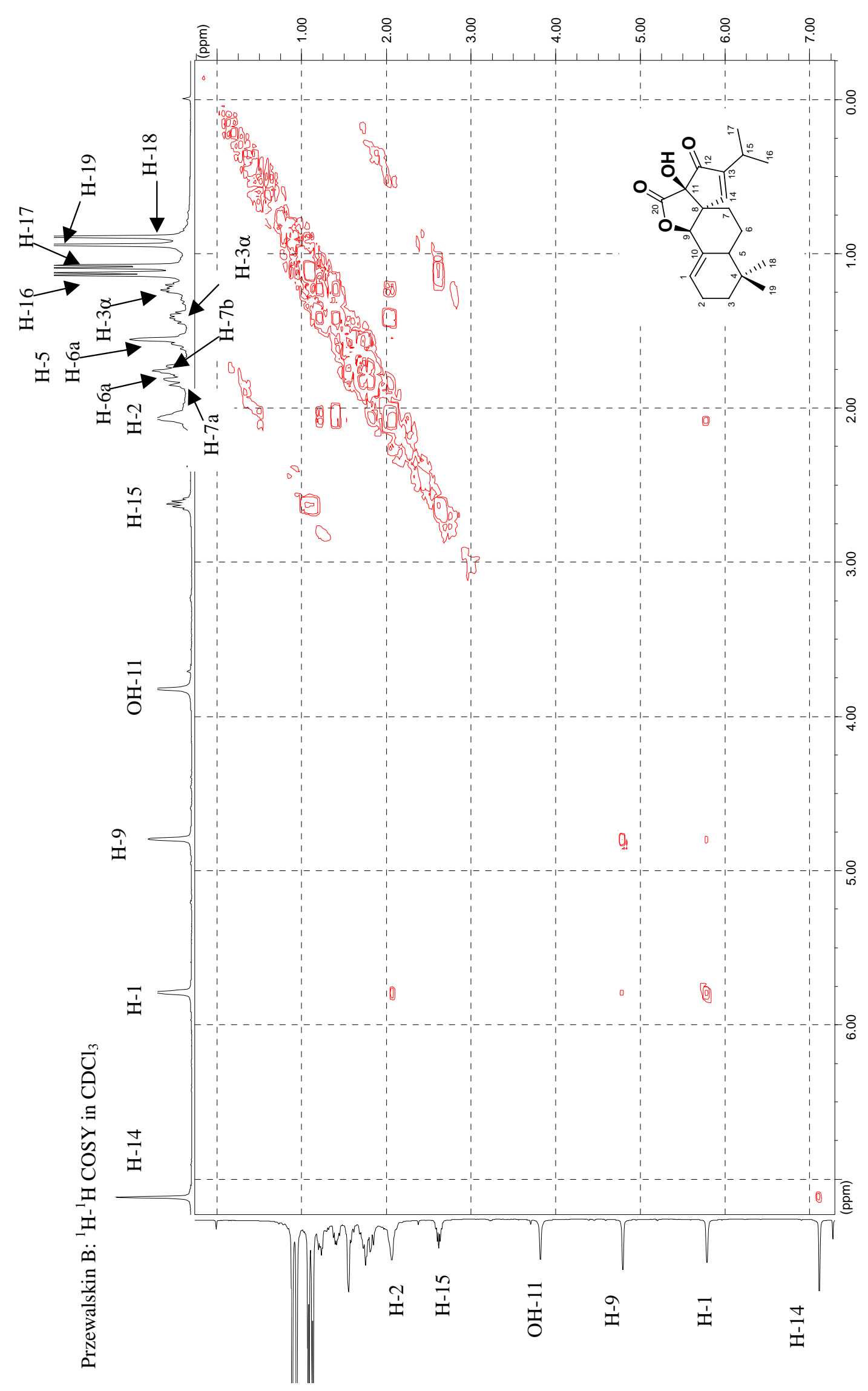




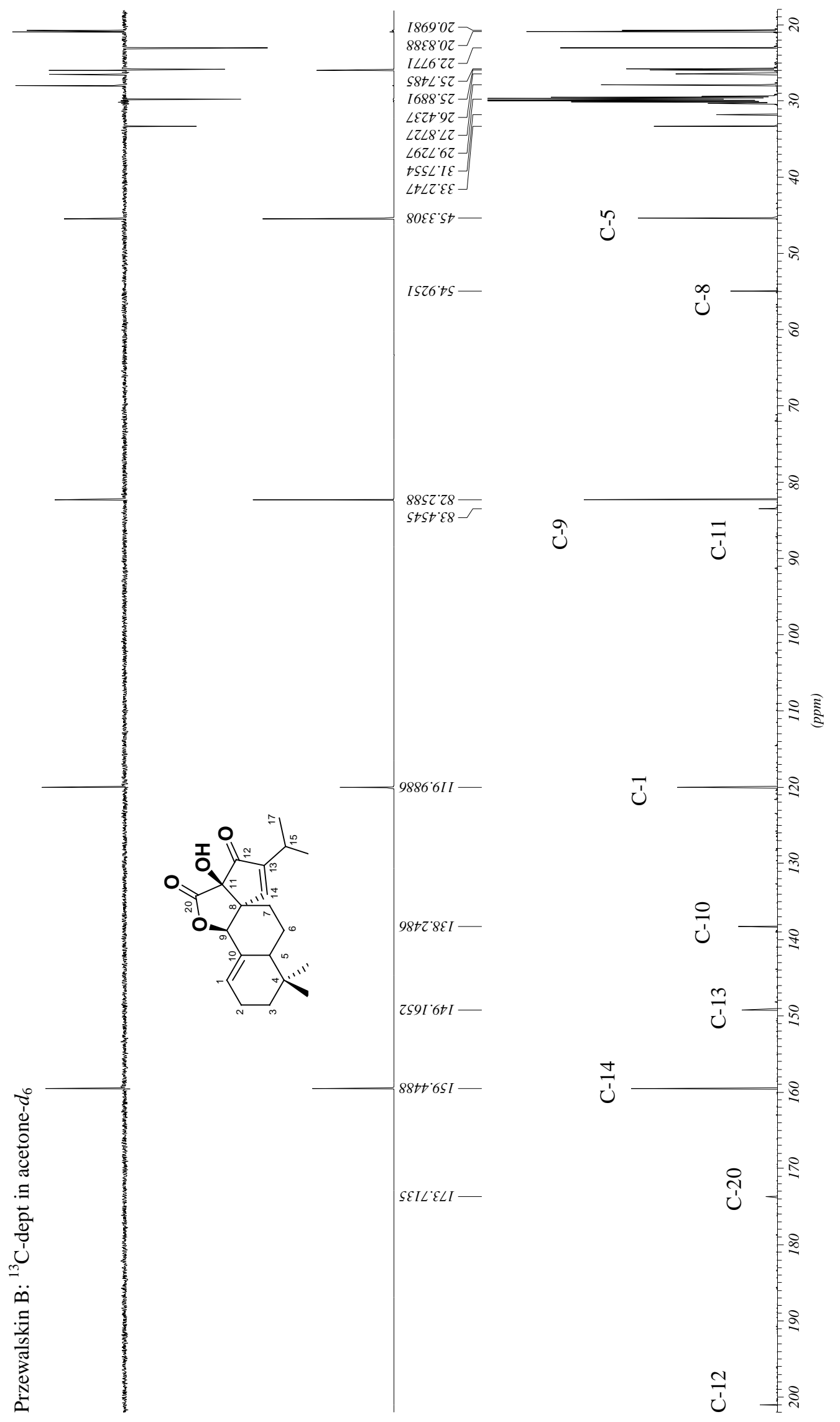




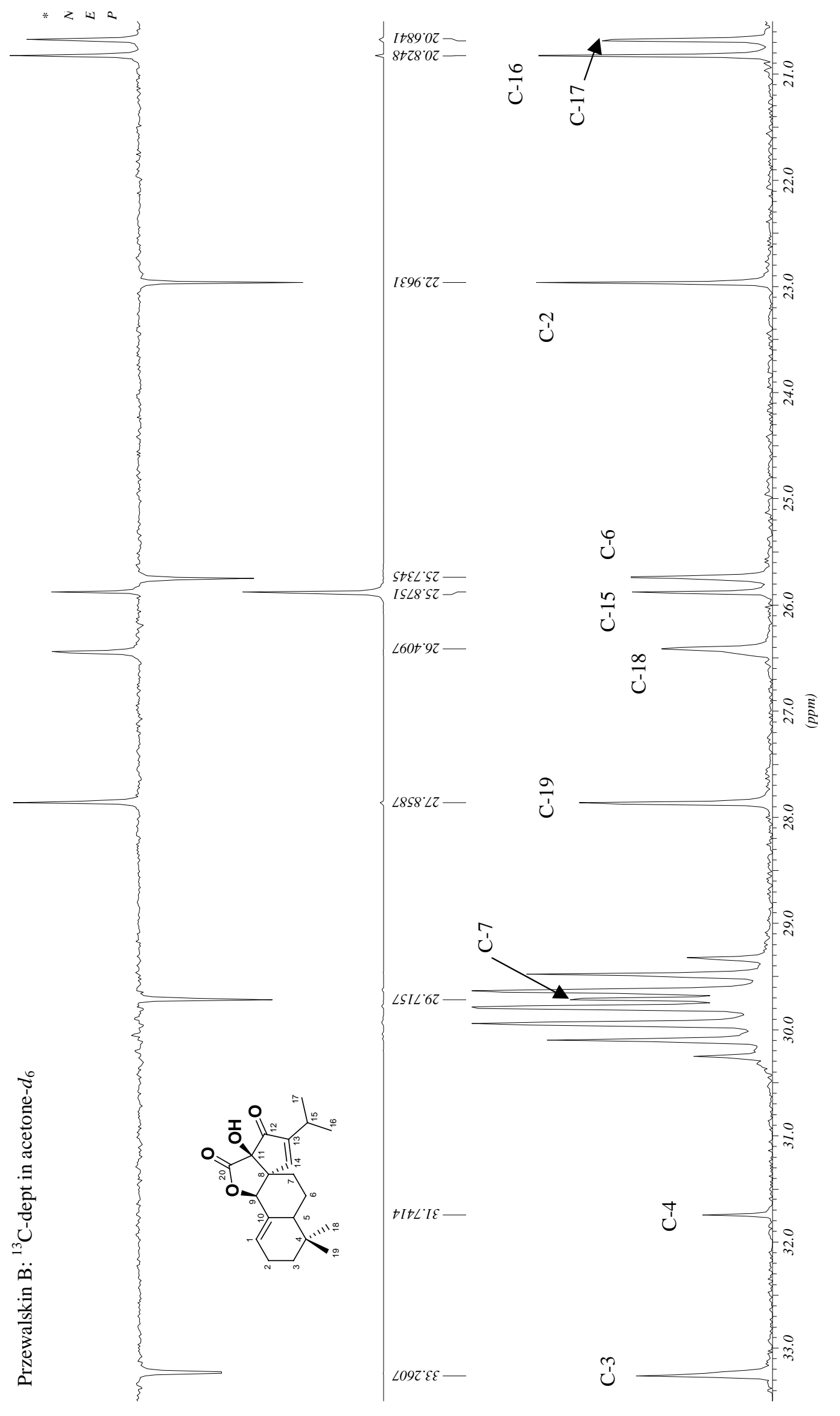




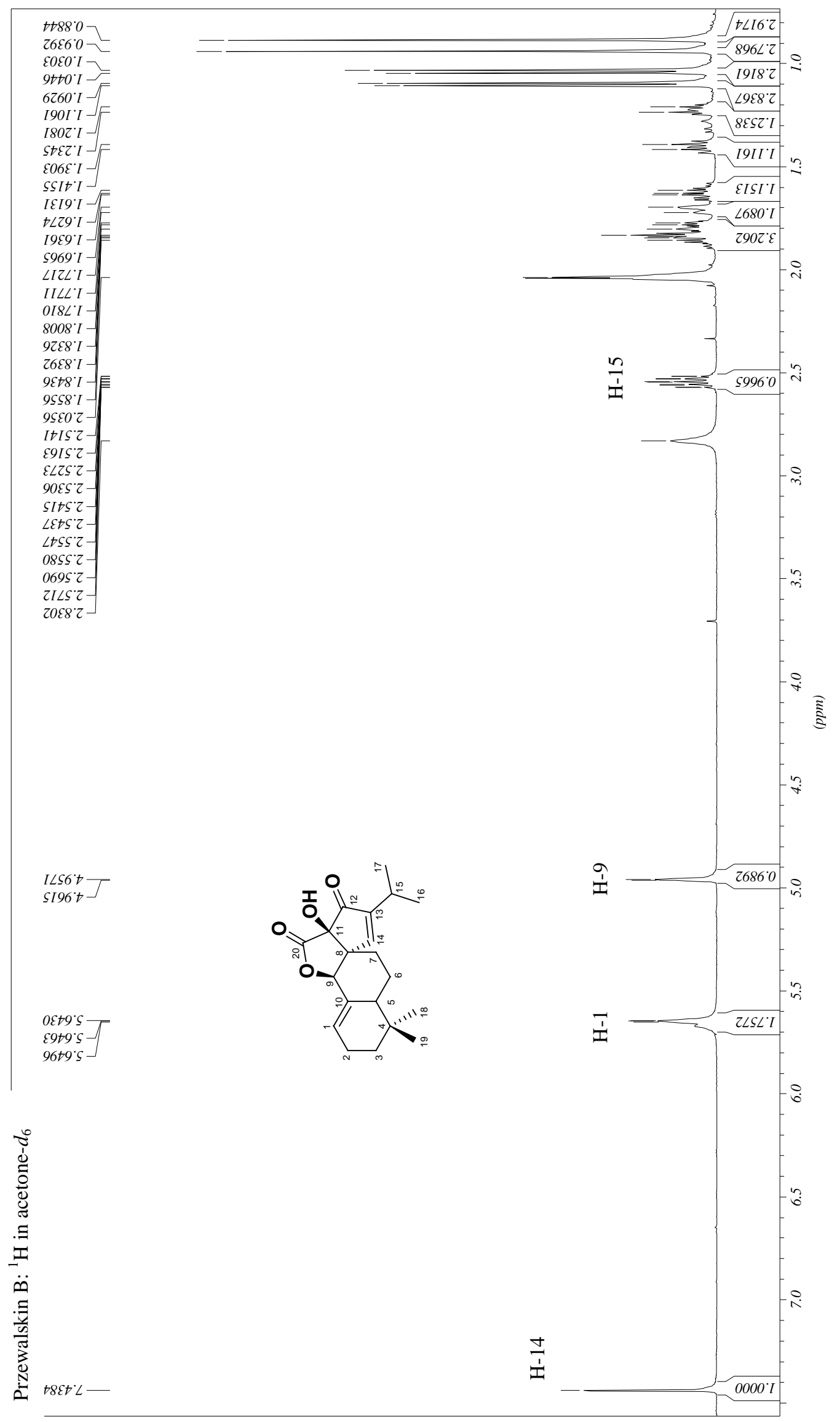




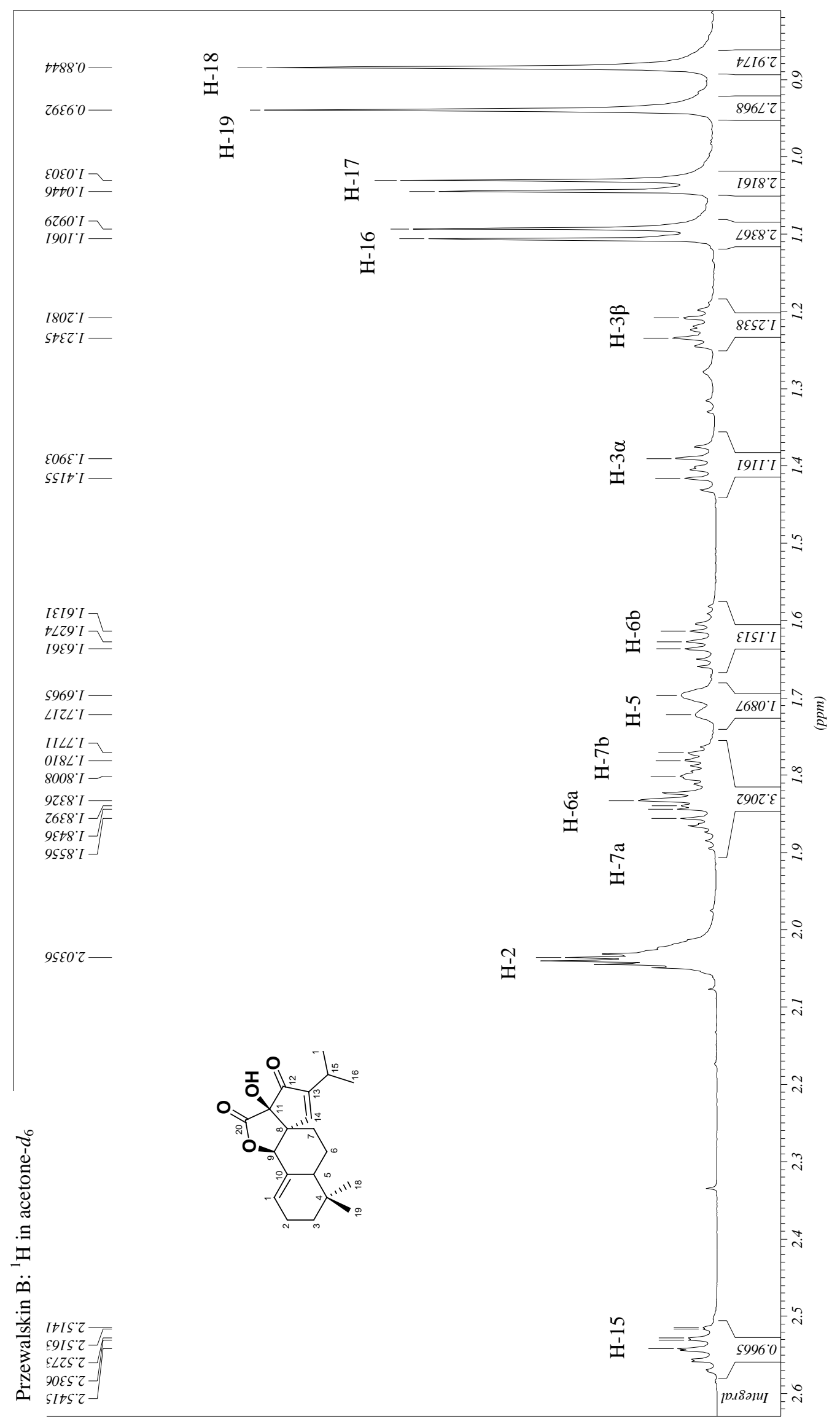




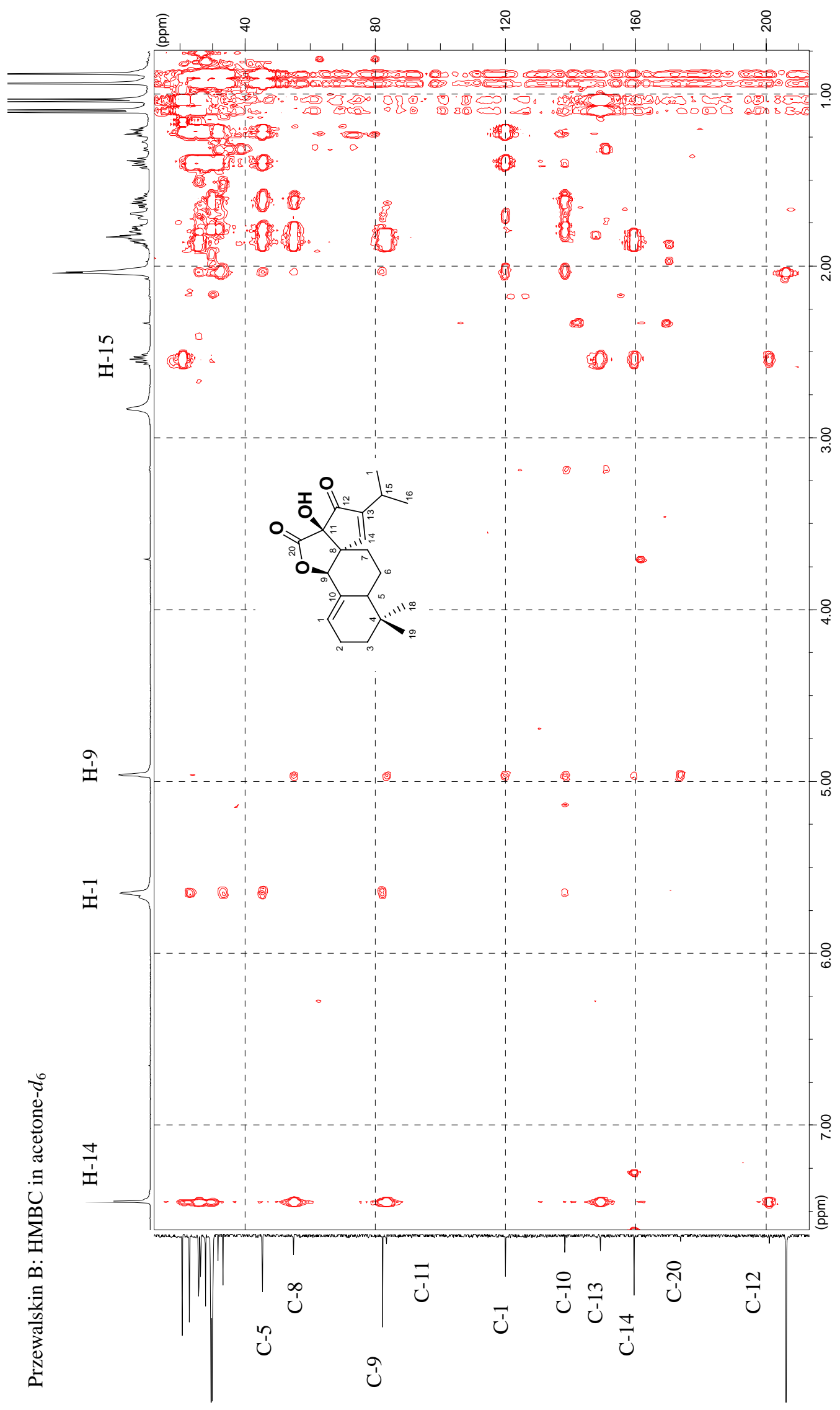




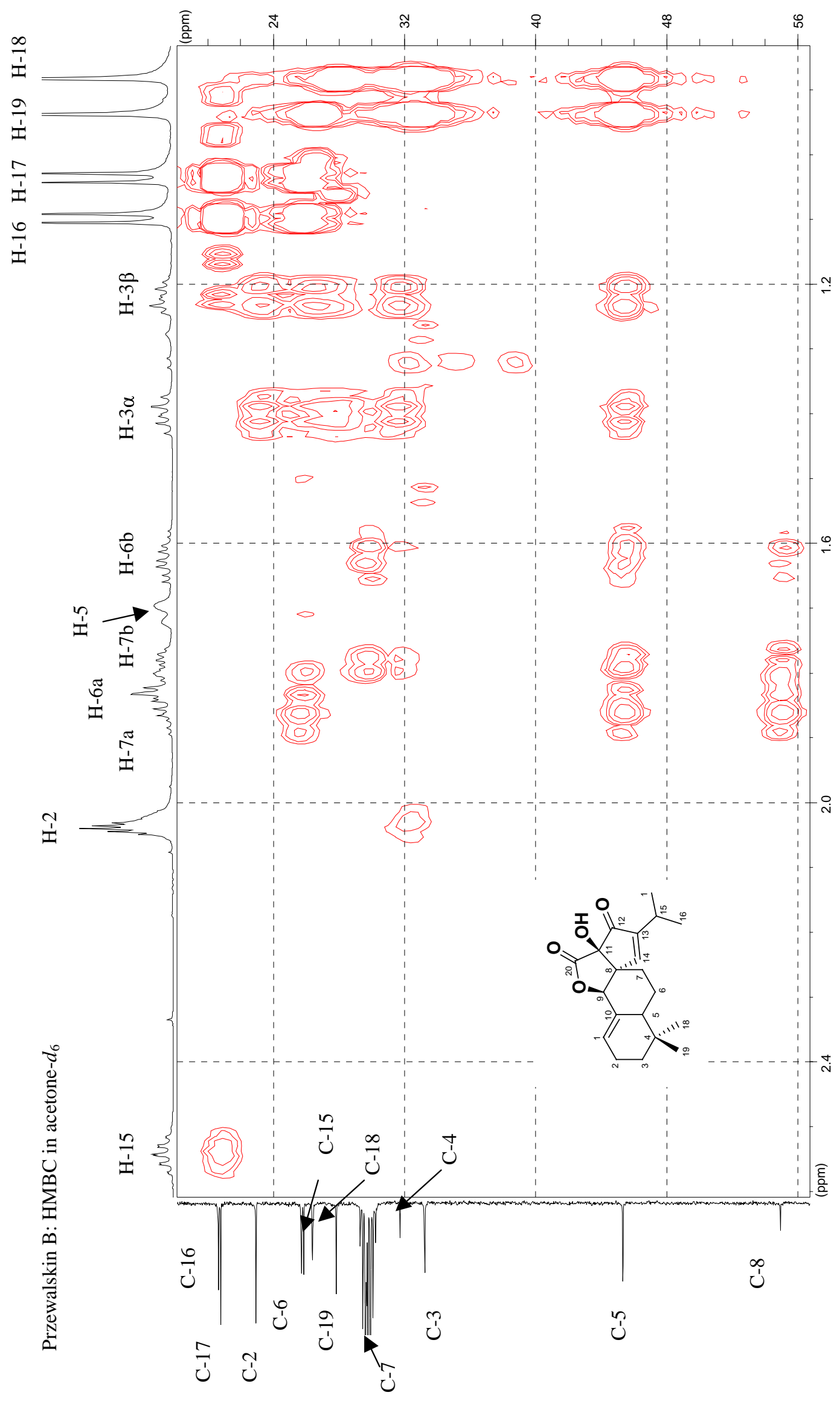




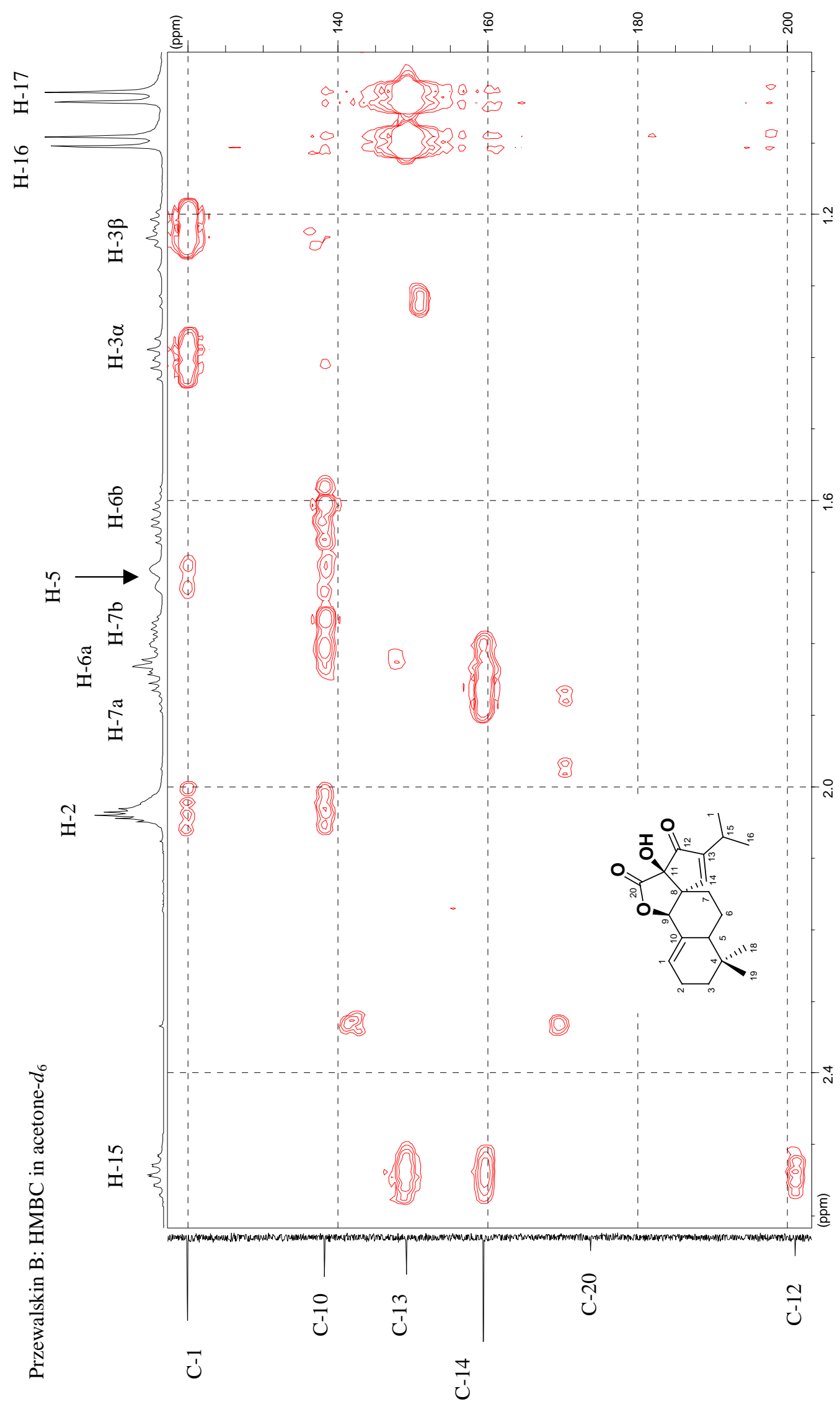

